\title{
Histopathological study on right endomyocardial biopsy of Kawasaki disease
}

\author{
CHIKAO YUTANI, KINYA OKANO, TETSURO KAMIYA, KOHKI OGUCHI, \\ TAKAHIRO KOZUKA, MITSUSHIGE OTA, SHUNZO ONISHI
}

\begin{abstract}
From the Departments of Pathology, Paediatrics, and Radiology, National Cardiovascular Centre, Osaka University Medical School, Osaka, Fapan
\end{abstract}

SUMMARY Fifty right ventricular endomyocardial biopsy specimens taken from patients withKawasaki disease were studied. These were taken from 33 male and 17 female patients.

Biopsies were examined for inflammatory cell infiltration, fibrosis, myocardial fibre disarrangement, and the cellular and nuclear changes of hypertrophy. A score of severity was prepared. The degree of abnormality was found to correlate with the duration of the disease, as did fibrosis found in 18 cases $(36 \%)$, but inflammatory cell infiltration did not (13 cases, $26 \%$ ).

Coronary involvement was restricted to the male patients but the myocardial changes occurred in both sexes.

In 1974, Kawasaki and his colleagues ${ }^{1}$ reported a new disease which they had observed over some years. Children presented with fever, conjunctival congestion, pharyngitis, lipoedema, cervical lymphadenopathy, and a polymorphous exanthematous rash on the trunk. Though the disease was initially thought to be benign it became apparent that a proportion of patients died suddenly. Detailed morphological studies of the heart at necropsy were widely reported. ${ }^{2-6}$ Such studies showed death to be related to a generalised myocarditis which may include the atrioventricular conduction system and an intense coronary arteritis, the latter leading to ischaemic myocardial damage or actual coronary artery rupture with haemopericardium.

The disease remains of unknown aetiology and the prognosis is still unresolved. Death may be related as much to the myocarditic element as to the coronary arterial component.

This hypothesis is supported by the present paper. Fifty right ventricular endomyocardial biopsies taken from patients with Kawasaki disease were examined. All showed myocardial architectural disorganisation with hypertrophy on histological examination, and the findings suggest that such changes are progressive.

\section{Subjects and methods}

Right ventricular endomyocardial biopsies obtained at cardiac catheterisation from 50 patients with Received for publication 26 November 1979
Kawasaki disease were collected and studied at the Department of Pathology, National Cardiovascular Center in 1978 and 1979.

In all patients, the clinical diagnosis was based upon agreement with the guidelines prepared by the Mucocutaneous Lymph Node Syndrome (MCLS) Research Committee of the Ministry of Health and Welfare of the Japanese Government in 1974.

In addition to physical and radiological examination, investigation included echocardiography and selective coronary angiography. The age and sex distribution at onset are shown in Fig. 1. Those patients with radiologically abnormal coronary arteries are indicated. All were male. Fig. 2 analyses the length of history.

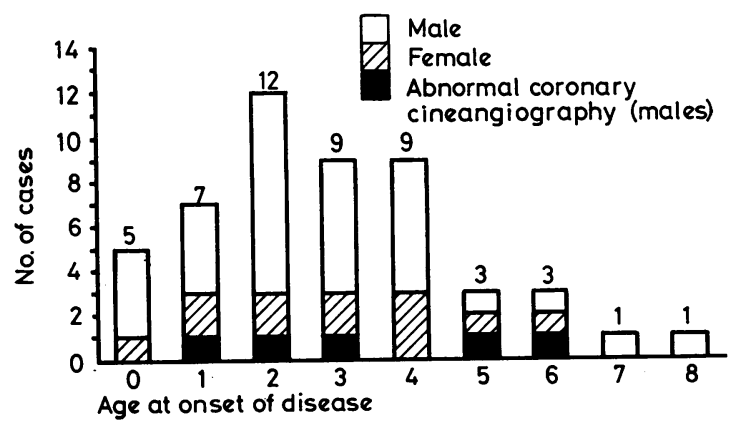

Fig. 1 Age distribution at onset of Kawasaki disease. 
Biopsy specimens were taken from the free wall of the right ventricle using Konno's biotome. One specimen was placed in buffered 10 per cent formalin for paraffin section, the other in 2.5 per cent glutaraldehyde for study by electron microscopy.

Tissue blocks were sectioned at a thickness of

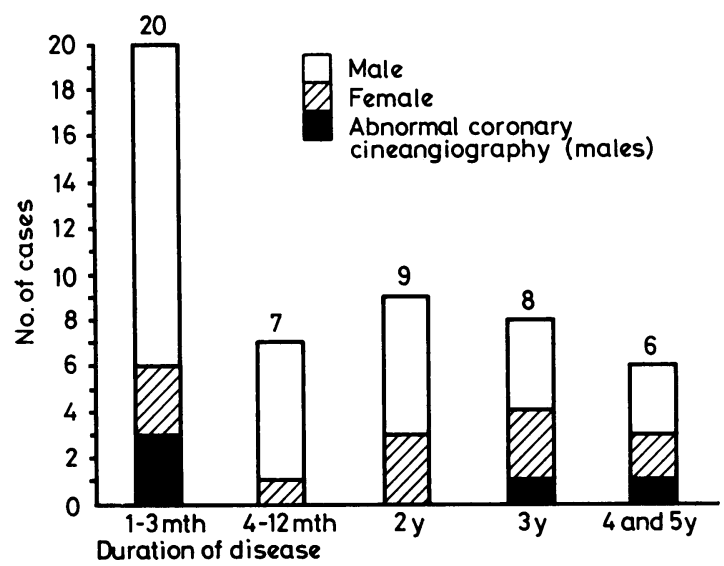

Fig. 2 Duration of disease before endocardial biopsy. approximately $5 \mu$ and stained with haematoxylineosin, periodic acid-Schiff, and trichrome.

The histological criteria of myocardial morphology studied were those of Okada, ${ }^{7}$ Sekiguchi and Konno, ${ }^{8}$ and Van Noorden et al. ${ }^{9}$ Each of these criteria was graded 0 to 3 according to severity and the total scores were plotted. Each individual component of the score represented the total scores of three independent observations. Typical findings are illustrated in Fig. 3. The presence of inflammatory changes and of fibrosis were also noted.

Lastly, five biopsies taken from other subjects, which were collected to show normal myocardium, were also subjected to the scoring procedure for abnormal myocardial morphology. These were used as controls.

\section{Results}

(1) INFLAMMATORY LESIONS (Fig. 4)

Inflammatory cell infiltration was found in 13 cases $(26 \%)$. It was slight and consisted of small lymphocytes and occasional plasma cells. No acute or active inflammatory changes were seen. The presence of these infiltrates seemed to be unrelated to the duration of the disease.

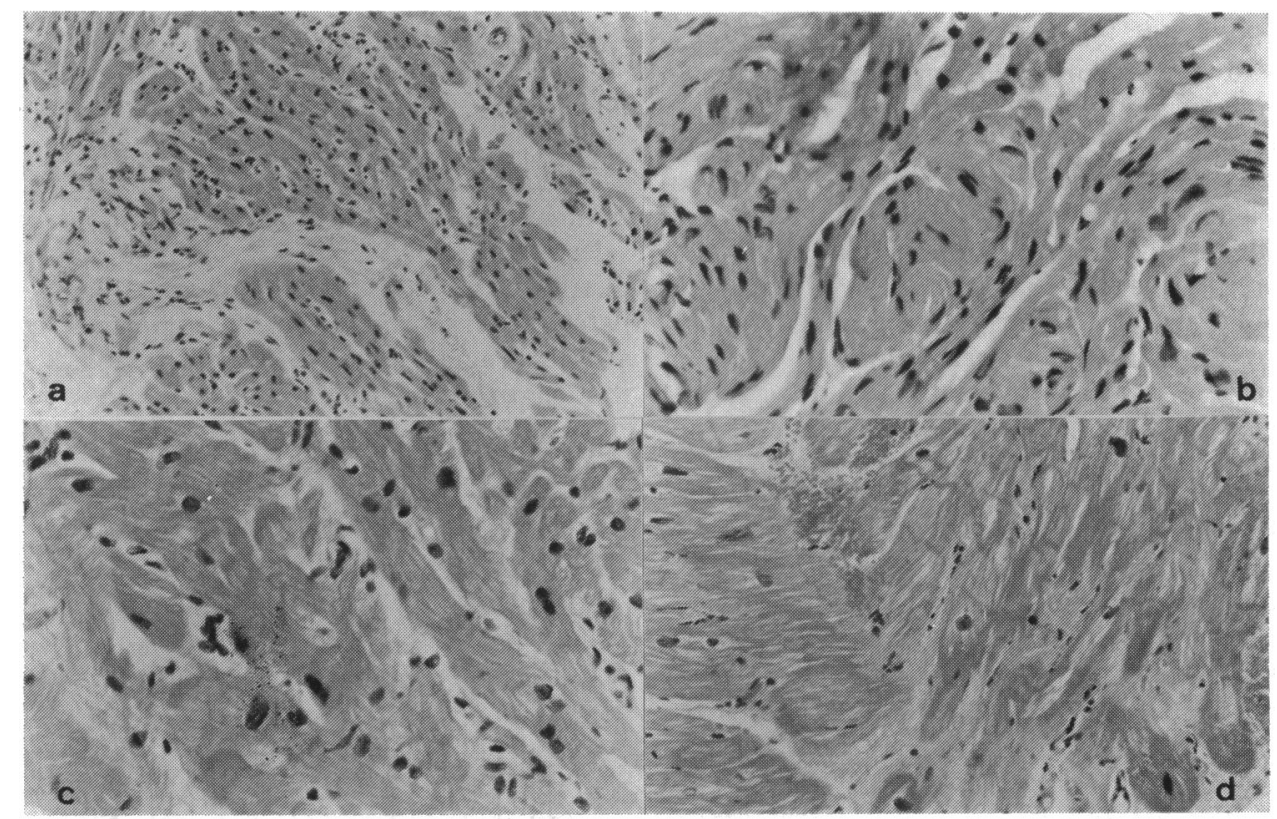

Fig. 3 Typical biopsy findings: (a) obvious disarray of myocardial fibres with nuclear proliferation, swelling, and duplication ( $H$ and $E$, original magnification $\times 100)$; (b) myocardial whorling ( $H$ and $E$, original magnification $\times$ 100 ): (c) varying size of the myocardial fibres and nuclei, with abnormal branching ( $H$ and $E$, original magnification $\times 400$ ); (d) myocardial hypertrophy with disarray and fibrosis ( $H$ and $E$, original magnification $\times 400)$. 
(2) FIBRosis (Fig. 5)

Eighteen cases $(36 \%)$ showed fibrosis of varying degree and the incidence seemed to be related to the duration of the disease.

\section{(3) TOTAL SCORES OF HISTOLOGICAL}

\section{FINDINGS}

Individual scores are plotted against duration of the disease in Fig. 6.

The coefficient of correlation is only 0.59 $(p<0.05)$. The five cases with abnormal coronary cineangiograms are included in Fig. 6. Fig. 7 shows an example from a case biopsied five years after the onset of the disease.

\section{Discussion}

In Kawasaki disease, in addition to necrotising coronary arteritis with thrombosis, there is also myocarditis. ${ }^{36}$

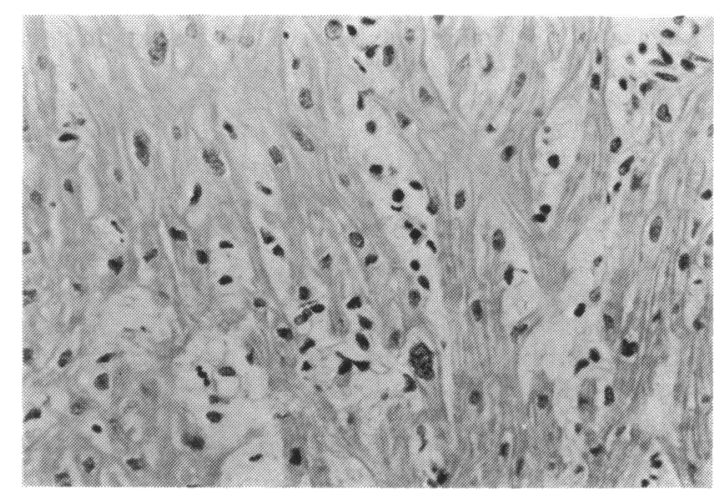

Fig. 4 Inflammatory small cell infiltration in the interstitial tissue and lace-like changes in the myocardial fibres ( $H$ and $E$, original magnification $\times 200$ ).

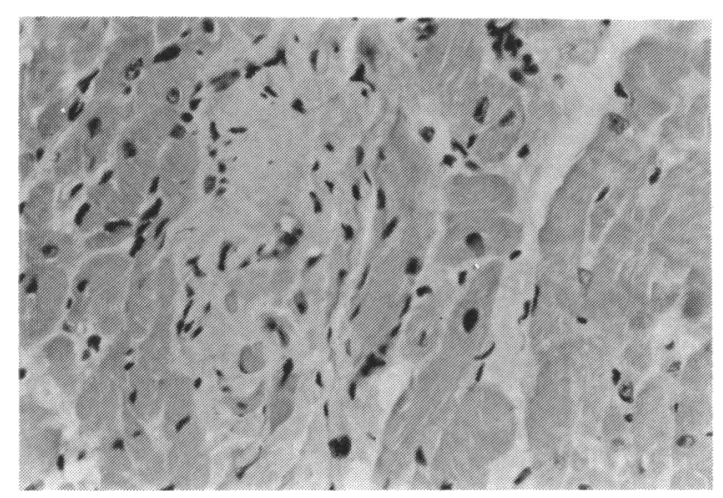

Fig. 5 Focal fibrosis involving several myocardial fibres $(H$ and $E$, original magnification, $\times 200$ ).
This extends into the interstitial tissue and results in myocardial oedema, and degeneration; it has been elegantly demonstrated by immunofluorescence techniques which have shown diffuse deposits of myocardial intracellular IgG. ${ }^{3}$

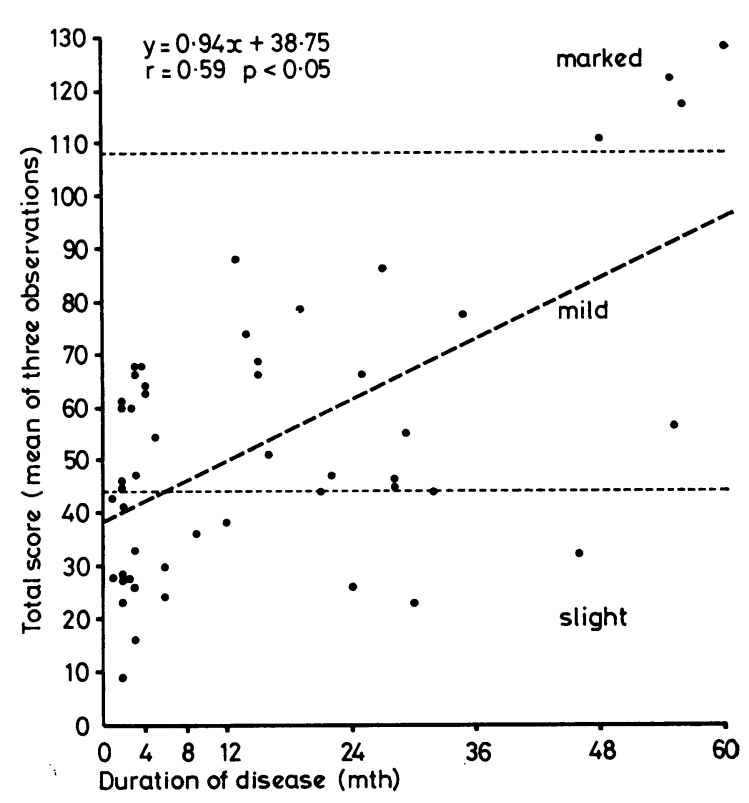

Fig. 6 Correlation of abnormal myocardial morphology score and duration of the disease.

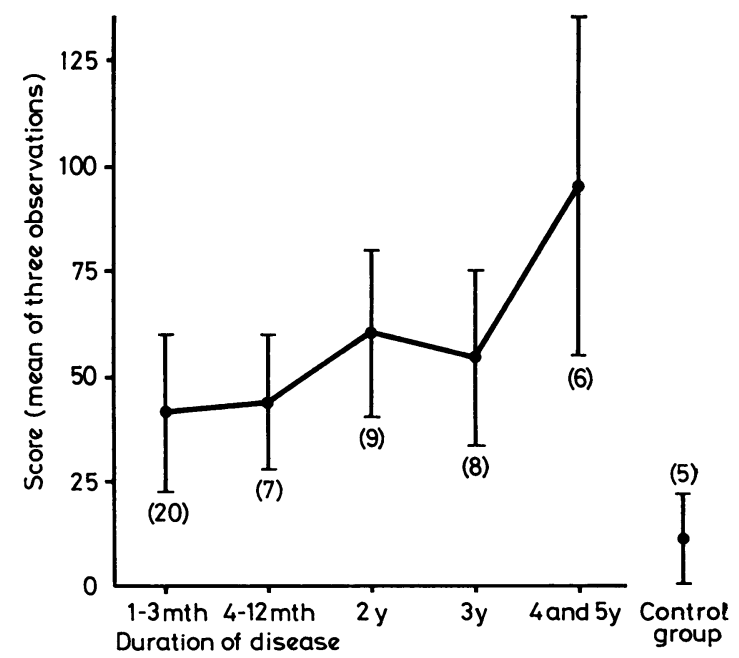

Fig. 7 Abnormal myocardial morphology score and duration of disease. 
Tanaka et al. ${ }^{2}$ consider it to be a pancarditis. Most cases coming to necropsy we found to have died from ischaemia caused by the necrotising arteritis, which is thought to be similar to that found in infantile periarteritis nodosa. ${ }^{25}$ Myocarditis receives little mention but it is possible its persistence is the cause of part, at least, of the myocardial changes which occur in the course of the disease. In our study, chronic interstitial myocarditis did not correlate with the duration of the disease. Interstitial fibrosis which can be distinguished from ischaemic myocardial fibrosis was related to duration and may follow the myocarditis. Perhaps the primary pathology in Kawasaki disease is an inflammatory process which can affect either the coronary arteries or the myocardium and interstitial tissue.

Our review of the myocardial changes also included assessment of myocardial fibre hypertrophy or arrangement. Myocardial hypertrophy and disarray also correlate with duration and it was clear that the overall myocardial abnormality was related to duration.

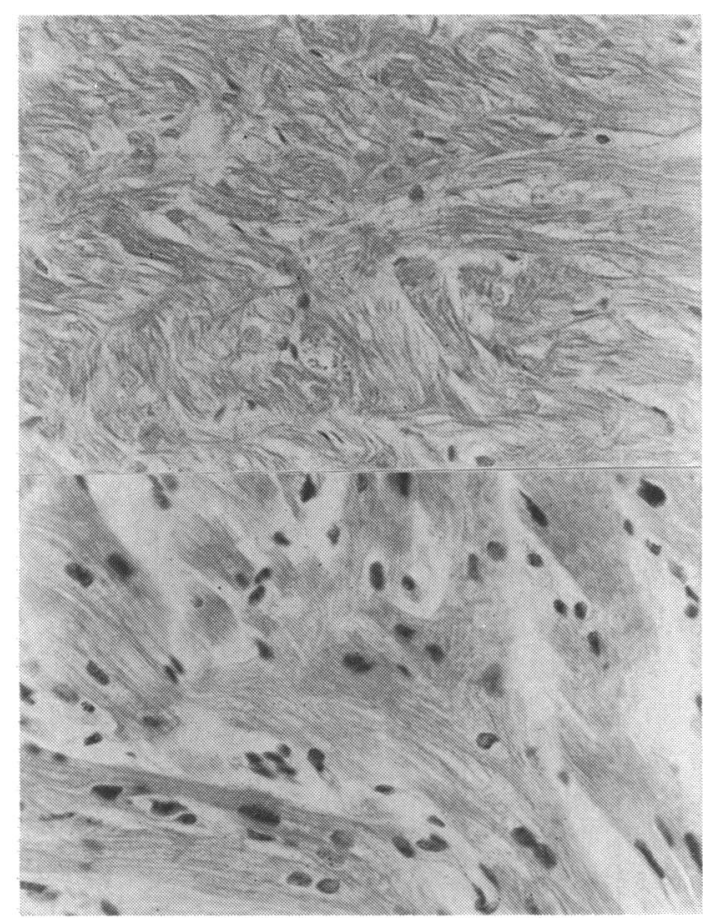

Fig. 8 Severe histological changes in a case of five years' standing ( $H$ and $E$, original magnification $\times 400$ ).
In long-standing cases, some biopsies showed such abnormality of arrangement including whorling that HOCM was simulated histologically. The mechanism of protection of such changes is poorly understood at present. Abelmann, ${ }^{10}$ among others, has shown similar disarray after viral myocarditis.

Kawasaki disease occurs more often in men than in women, but though the involvement of the coronary arteries was restricted to the male patients, the myocardial changes were present in both sexes.

If the disease is caused by infection, the aetiological agent, whether viral, rickettsial, bacterial, or fungal, remains to be discovered, and the importance of this relative to the coronary arteries, particularly of small vessels beyond the reach of coronary angiography, remains unresolved.

\section{References}

${ }^{1}$ Kawasaki T, Kosaki F, Okawa S, Shigematsu I, Yangagawa $H$. A new infantile acute febrile mucocutaneous lymph node syndrome (MLNS) prevailing in Japan. Pediatrics 1974; 54: 271-6.

${ }^{2}$ Tanaka N, Sekimoto K, Naoe S. Kawasaki disease. Arch Pathol Lab Med 1976; 100: 81-6.

${ }^{3}$ Hamashima Y. Kawasaki disease. Trans fpn Soc Pathol 1977; 66: 59.

${ }^{4}$ Melish ME, Hicks RM, Larson EJ. Mucocutaneous lymph node syndrome in the United States. $A m \mathcal{F} D$ is Child 1976; 130: 599-607.

${ }^{5}$ Landing BH, Larson EJ. Are infantile periarteritisnodosa with coronary artery involvement and fatal mucocutaneous lymph node syndrome the same? Comparison of 20 patients from North America with patients from Hawaii and Japan. Pediatrics 1977; 59: 651-62.

${ }^{6}$ Fujiwara H, Hamashima Y. Pathology of the heart in Kawasaki disease. Pediatrics 1978; 61: 100-7.

${ }^{7}$ Okada R. A morphological classification of idiopathic myocardiopathy and allied cardiac diseases. Nippon funkankigaku Shi 1971; 35: 755-63.

${ }^{8}$ Sekiguchi M, Konno S. Diagnosis and classification of primary myocardial disease with the aid of endomyocardial biopsy. Nippon funkankigaku Shi 1971; 35: 737-54.

${ }^{9}$ Van Noorden S, Olsen EGJ, Pearse AGE. Hypertrophic obstructive cardiomyopathy, a histological, histochemical, and ultrastructural study of biopsy material. Cardiovasc Res 1971; 5: 118-31.

${ }^{10}$ Abelmann WH. Viral myocarditis and its sequelae. Annu Rev Med 1973; 24: 145-52.

Requests for reprints to Dr C Yutani, Department of Pathology, National Cardiovascular Centre, 5125 Fujishirodai, Suita, Osaka 565, Japan. 